concentration and the two other major mortality categories in this study-deaths from coronary heart disease and alcohol related deaths-is notable. Nevertheless, the published evidence for raised uric acid concentration as a risk factor for coronary heart disease is conflicting. ${ }^{9}$

Alcohol, on the other hand, is usually considered to raise the serum urate concentration. Alcoholics have an increased incidence of hyperuricemia, ${ }^{10}$ and hyperuricemia in clinical settings is regarded as an indicator of alcohol abuse. ${ }^{11}{ }^{12}$ According to Lieber, alcohol raises the lactate concentration in serum thus hampering the renal excretion of uric acid. ${ }^{13}$ One study, however, reported an enhanced renal excretion of uric acid in liver cirrhosis ${ }^{14}$ and in some population studies no correlation is found between (self reported) alcohol consumption and serum urate concentration. ${ }^{1516}$ Our findings indicate that there are no strong associations between raised serum urate concentration and advanced stages of alcohol related diseases.

Further studies are necessary to substantiate the relation between urate and fatal neoplasia in larger groups with different types of tumours. The clinical significance of the findings may be limited because of the need for large, age and sex matched reference materials. Nevertheless, monitoring longitudinal changes in serum urate and cholesterol concentrations in conjunction with other risk indicators such as cigarette smoking and hereditary factors may be of practical use for the early detection or prevention of cancer. Furthermore, the results may be of theoretical interest as they weigh against recent suggestions that serum uric acid has an antioxidant protective effect against cancer. ${ }^{8}$

This study was supported by the Swedish Council for Planning and Coordination of Research and by the Kristianstads County Council.

\section{References}

1 Petersson B, Trell E, Sternby NH. Low cholesterol level as risk factor for non-coronary mortality in middle-aged men. $\mathcal{F} A M A 1981 ; 245$ : 2056-7.

${ }^{2}$ Rose G, Shipley MJ. Plasma lipids and mortality: a source of error. Lancet 1980; :523-6.

${ }^{3}$ Kark JD, Smith AH, Hames CG. The relationship of serum cholesterol to incidence of cancer in Evans County, Georgia. $f$ Chronic Dis 1980; 33:311-22.

4 Petersson B, Krantz P, Kristensson H, Trell E, Sternby NH. Alcoholrelated death: a major contributor to mortality in urban middle-aged men. Lancet 1982 ;ii : 1088-90.

- Maxwell AE. Analyzing qualitative data. London: Methuen, 1961.

- Seegmiller JE. Disorders in purine and pyrimidine metabolism. In: Bondy PK, Rosenberg LE, eds. Metabolic control and disease. Philadelphia: Saunders, 1980:780.

${ }^{7}$ Fessel WJ, Siegelaub AB, Johnson ES. Correlates and consequences of asymptomatic hyperuricemia. Arch Intern Med 1973;132:44-54.

${ }^{8}$ Ames BN, Cathcart R, Schiewers E, et al. Uric acid provides an antioxidant defense in humans against oxidant- and radical-caused aging and cancer: a hypothesis. Proc Natl Acad Sci USA 1981;11:6858-62.

- Persky VW, Dyer A, Idris-Soven E, et al. Uric acid: a risk factor for coronary heart disease ? Circulation 1979;59:969-77.

10 Olin JS, Devenyi P, Weldon KL. Uric acid in alcoholics. Quarterly fournal of Studies on Alcohol 1973;34:1202-7.

11 Drum DE, Goldman PA, Jankowski CB. Elevation of serum uric acid as a clue to alcohol abuse. Arch Intern Med 1981;141:477-9.

12 Ramsay LE. Hyperuricemia in hypertension: role of alcohol. $\mathrm{Br} \mathrm{Med} \mathfrak{f}$ 1979 ; :643-4.

13 Lieber CS, Jones DP, Losowsky MS, et al. Interrelation of uric acid and ethanol metabolism in man. $\mathcal{f}$ Clin Invest $1962 ; 41: 1863-70$.

${ }^{14}$ Higuchi $T$, Nakamura T, Uchino $H$. Enhanced renal clearance of uric acid in hepatic cirrhosis. Isr F Med Sci 1981;17:1015-8.

15 Munan L, Kelley A, Petitclerc C. Population serum urate levels and their correlates. The Sherbrooke regional study. Am $\mathcal{F}$ Epidemiol 1976;103: 369-82.

16 Bengtsson C, Tibblin E. Serum uric acid levels in women. Acta Med Scand 1974;196:93-102.

(Accepted 20 April 1983)

\title{
Electrocardiographic chest wall mapping in the diagnosis of coronary artery disease
}

\author{
A M SALMASI, A N NICOLAIDES, R J VECHT, W G HENDRY, SAJIDA N A SALMASI, \\ E P NICOLAIDES, P H KIDNER, E M M BESTERMAN
}

\begin{abstract}
Chest wall mapping of ST segment changes, inverted $U$ waves, and $Q$ waves using 16 electrocardiographic electrodes was performed at rest and during and after bicycle ergometry in 150 patients presenting with chest pain suggestive of angina. All patients underwent coronary angiography. The presence or absence of appreciable
\end{abstract}

\footnotetext{
Academic Surgical Unit, Cardiovascular Unit, Cardiovascular Laboratory, and Waller Cardiopulmonary Unit, St Mary's Hospital Medical School, London W2

A M SALMASI, MB, PHD, senior research fellow

A N NICOLAIDES, MS, FRCS, reader in vascular surgery

R J VECHT, MRCP, consultant cardiologist

W G HENDRY, MRCP, senior registrar

SAJIDA N A SALMASI, BSC, research fellow

E P NICOLAIDES, BSC, MB, research fellow

P H KIDNER, FRCP, consultant cardiologist

E M M BESTERMAN, MD, FRCP, consultant cardiologist
}

Correspondence and reprint requests to: $\mathrm{Mr} \mathrm{A} \mathrm{N}$ Nicolaides, Director, Cardiovascular Laboratory, St Mary's Hospital Medical School, London W2. coronary artery disease ( $\geqslant 50 \%$ stenosis) was detected with a sensitivity of $98 \%$ and a specificity of $88 \%$. The identification of lesions in individual coronary arteries was also possible with a sensitivity and specificity of $87 \%$ and $85 \%$ respectively for the territory of the left anterior descending and diagonal artery, $71 \%$ and $85 \%$ respectively for the right coronary artery, and $85 \%$ and $80 \%$ respectively for the circumflex artery.

This test appears to be a reliable non-invasive screening method for selecting patients for angiography.

\section{Introduction}

The high incidence of false positive and false negative results obtained with electrocardiographic exercise testing ${ }^{1}$ has stimulated investigators to use a variety of lead systems and different criteria for ischaemia to improve the predictive accuracy. Fox et al suggested that 16 lead isopotential precordial surface mapping recorded before and immediately after exercise is superior to recordings made with orthogonal and single chest leads. ${ }^{2-6} \mathrm{~A}$ recent attempt to predict the severity of coronary artery disease by using the slope of submaximal ST segment/ 
heart rate relationship produced promising results. ${ }^{7}$ Despite the increased sensitivity of these methods, however, relatively little information has been provided about ischaemia in individual coronary artery territories.

The object of our study was to test the hypothesis that electrocardiographic mapping of the chest wall obtained at rest and during and after bicycle ergometry used with a combination of criteria for myocardial ischaemia (ST segment depression $^{8}$ and inverted $U$ waves ${ }^{9}$ ) and previous myocardial infarction ( $Q$ waves ${ }^{10}$ ), would increase the sensitivity of the test. In addition, we wanted to establish whether by positioning the electrodes on the front and back of the chest wall we would obtain information about individual coronary artery territories.

\section{Patients and methods}

We studied by electrocardiographic bicycle ergometry 150 consecutive patients (136 men, 14 women) presenting with chest pain suggestive of angina. Each patient underwent coronary arteriography within seven days after the stress test. Patients with unstable angina, rest pain, evidence of hypertrophic cardiomyopathy, left ventricular hypertrophy, or intraventricular conduction defects were excluded, as were patients not in sinus rhythm, those receiving digoxin or antiarrhythmic treatment, and those who had had previous coronary surgery. Seventy five of the patients were taking beta adrenergic blocking agents at the time of the stress test.

Skin preparation and position of electrodes-The chest wall was shaved when necessary and the skin cleaned with acetone to ensure good contact with the disposable press stud electrodes; these were positioned in four vertical rows (figure). Electrode B1 was immediately below the left sternoclavicular joint. A1 was at the same level but $3 \mathrm{~cm}$ lateral to the right sternoclavicular joint. $\mathrm{C} 1$ and $\mathrm{D} 1$ were at the same horizontal level, with $\mathrm{Cl}$ on the anterior axillary line and D1 on the patient's back, $6 \mathrm{~cm}$ medial to the posterior axillary line. C3 was on the anterior axillary line at the fifth intercostal space corresponding to the conventional V5 position: this determined the horizontal level of $\mathrm{A} 3, \mathrm{~B} 3$, and D3. C2 was equidistant from $\mathrm{C} 1$ and C3 (distance $x$ ) and determined the horizontal level of A2, B2, and D2. $\mathrm{C} 4$ was at a distance $\mathrm{x}$ from $\mathrm{C} 3$ and determined the horizontal level of A4, B4, and D4. A reference lead was placed at the right infraclavicular fossa and an earth lead in the left midaxillary line just above the iliac crest.

This configuration of electrodes was different from that used previously, ${ }^{2-6}$ because the aim was to detect electrical changes originating in individual coronary artery territories-that is, the right (A1-A4), the left anterior descending or diagonal (B1-B4 and C1-C4), and the circumflex (D1-D4).

Exercise-Exercise was performed on an Elema Schonander bicycle ergometer at a constant speed of $60 \mathrm{rpm}$. The starting work load was $50 \mathrm{~W}$, which was increased by $25 \mathrm{~W}$ every two minutes up to $100 \mathrm{~W}$ and then by $25 \mathrm{~W}$ every minute until the end point, the end point being when the maximum predicted heart rate for the patient's age was achieved. Indications for stopping the exercise were the development of severe chest pain, ST segment depression $\geqslant 4 \mathrm{~mm}$, dyspnoea, exhaustion, threatening arrhythmias, and a decrease in systolic blood pressure.

Electrocardiographic recording and blood pressure monitoring-A standard 12 lead electrocardiograph was first recorded with the patient recumbent at rest to exclude any abnormality such as a recent silent myscardial infarction or an arrhythmia. Recordings from the 16 leads were obtained at rest and every minute during and after exercise until the heart rate and electrocardiographic changes had reverted to the pre-exercise state. The 16 leads were connected to a four channel amplifier (HP 8811A) and a four channel recorder (HP 7700) via a four way manual switch, which permitted simultaneous recordings from four leads. Blood pressure was measured at rest and every minute throughout the test with a sphygmomanometer.

Isopotential chest wall mapping-Changes in ST segments were mapped as isopotential areas of $1 \mathrm{~mm}, 2 \mathrm{~mm}, 3 \mathrm{~mm}$, or more for every minute of the test (figure). The presence of $Q$ waves at rest and the appearance of inverted $U$ waves during exercise were also mapped (figure). The ST segment was considered to be depressed if it was $\geqslant 1 \mathrm{~mm}$ below the isoelectric line and its duration after the $\mathrm{J}$ point was $\geqslant 0.08 \mathrm{~s}$. ${ }^{11} \mathrm{~A} \mathrm{Q}$ wave was considered to be significant if its duration was $\geqslant 0.04 \mathrm{~s}$ or its amplitude was $\geqslant 25^{\circ}$ of the amplitude of the $R$ wave, ${ }^{10}$ or both. An inverted $U$ wave induced by exercise was considered to be significant if there was a discrete negative deflection within the TP segment, negative to the PR segment and separate from the $T$ and $P$ waves. ${ }^{9}$ The electrocardiographic changes were interpreted and drawings of isopotential areas made by members of the team who were unaware of the angiographic findings. It is argued that ST segment depression will not occur in a previously infarcted area. Such an area is recognisable by the presence of $Q$ waves, which indicate, in most cases, total or partial obstruction of the coronary artery supplying that territory. The appearance of inverted $U$ waves during exercise was included as a criterion because, although uncommon, it indicates myocardial ischaemia. ${ }^{\circ}$

Coronary arteriography-All patients in the study underwent left ventriculography and coronary arteriography according to the technique of Judkins ${ }^{12}$ or Sones and Shirey. ${ }^{13}$ A coronary lesion was considered to be haemodynamically significant if occlusion or stenosis was $\geqslant 50^{\circ}{ }_{0}$. The members of the team who interpreted the angiograms were not aware of the electrocardiographic findings. Patients with stenosis of the left main stem were classified as having the equivalent to disease of the left anterior descending or diagonal artery, or both, plus disease of the circumflex artery.

\section{Results}

Coronary angiography showed the presence of appreciable coronary lesions-that is, lesions with occlusion or stenosis $\geqslant 50 \%$ of the diameter of the lumen-in 124 patients. The remaining 26 patients had either normal coronary arteries or lesions with less than $50 \%$ stenosis. The exercise electrocardiograph yielded a sensitivity of $98 \%$ and a specificity of $88^{\circ} \%$ (table I).

TABLE I-Accuracy of electrocardiographic exercise test in detecting coronary heart disease

\begin{tabular}{|c|c|c|c|}
\hline \multirow[b]{2}{*}{ Result of angiography } & \multicolumn{2}{|c|}{ Result of test } & \multirow{2}{*}{$\begin{array}{c}\text { No of } \\
\text { patients }\end{array}$} \\
\hline & Positive & Negative & \\
\hline $\begin{array}{l}\text { All coronary arteries } \\
\text { Occlusion or } \geqslant 50^{\circ} \text { "stenosis in any artery } \\
\text { Normal coronaries or lesions with }<50^{\circ} \text { " stenosis }\end{array}$ & $121\left(98^{\circ}\right)$ & $23\left(88^{3}{ }_{0}\right)$ & $\begin{array}{r}124 \\
26\end{array}$ \\
\hline \multicolumn{4}{|c|}{$\begin{array}{l}\text { Left anterior descending or diagonal coronary artery, or both } \\
\text { (leads } B 1-B 4 \text { and } C 1-C 4)\end{array}$} \\
\hline $\begin{array}{l}\text { Occlusion or } \geqslant 50 \% \text {, stenosis in either artery } \\
\text { Normal or }<50 \% \text { stenosis in either artery }\end{array}$ & $113(97 \%)$ & 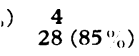 & $\begin{array}{r}117 \\
33\end{array}$ \\
\hline $\begin{array}{l}\text { Right coronary artery (leads } \\
\text { Occlusion or } \geqslant 50^{\circ} \text {, stenosis in right coronary artery } \\
\text { Normal or }<50^{\circ} \text {, stenosis in right coronary artery }\end{array}$ & $\begin{array}{l}s(-A 4) \\
\mathrm{y} \quad 60\left(71{ }^{\circ}\right) \\
10\end{array}$ & $\begin{array}{l}24 \\
56(85 \%)\end{array}$ & $\begin{array}{l}84 \\
66\end{array}$ \\
\hline $\begin{array}{l}\text { Circumflex coronary artery (lea } \\
\text { Occlusion or } \geqslant 50^{\circ} \text {, stenosis in circumflex coronary } \\
\text { Normal or }<50^{\circ}{ }^{\circ} \text { stenosis in circumflex coronary }\end{array}$ & $\begin{array}{l}\text { ads } D 1-D 4) \\
77\left(86^{\prime \prime}\right) \\
12\end{array}$ & $48\left(80^{\circ} \%\right)$ & $\begin{array}{l}90 \\
60\end{array}$ \\
\hline
\end{tabular}

Of the 124 patients with angiographically significant lesions, 117 had lesions of the left anterior descending or main diagonal artery, or both; 84 of the right coronary artery; and 90 of the circumflex artery (table I). Exercise electrocardiography had a sensitivity of $98 \%$ and a specificity of $88^{\circ}$, for lesions of the left anterior descending or main diagonal artery; a sensitivity of $71^{\circ}$ and a specificity of $85^{\circ}$ \% for lesions of the right coronary artery; and a sensitivity of $86 \%$ and a specificity of $80^{\circ} \%$ for lesions of the circumflex artery (table I). When ST segment depression in only lead C3 (conventional V5) was analysed the sensitivity was $71 \%$ and specificity $88 \%$.

The absence of appreciable coronary artery disease and the presence of single, double, or triple vessel disease was predicted correctly in 106 patients $\left(70_{\%}^{\circ}\right)$. In 37 patients $\left(25^{\circ}\right)$ errors occurred because the disease was missed or falsely diagnosed in a single coronary artery. Errors in more than one vessel occurred in the remaining seven ( $5^{\circ}$ ) patients (table II). Eleven patients had appreciable stenosis of the left main stem : exercise electrocardiography showed these patients to have disease of the left anterior descending or diagonal artery and of the circumflex artery. Eight of the patients also had appreciable stenosis in the right coronary artery; this was also correctly diagnosed (table II). In 14 of the 16 patients with triple vessel disease diagnosed as having double vessel disease (table II) exercise electrocardiography showed disease of the left anterior descending or diagonal artery and of the circumflex artery (table II).

Table III shows the electrocardiographic criteria for diagnosing disease in any of the three coronary arteries. An inverted $U$ wave or a $Q$ wave, or both, were the only criteria in 49 of the 250 lesions suggested by the electrocardiographic changes. ST segment depression 
TABLE II-Accuracy of electrocardiographic exercise test in detecting single, double, or triple vessel disease (figures in parentheses indicate numbers of patients with appreciable stenosis of left main stem)

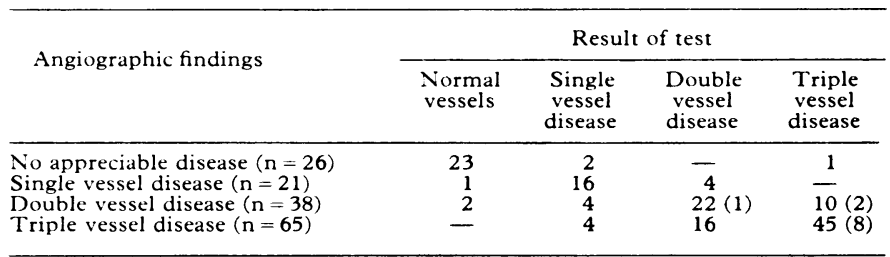

and $Q$ waves were responsible for false positive results in 16 and 19 arteries respectively. Inverted $U$ waves did not give rise to any false positive findings.

Seventy five patients (seven with normal vessels and 14 with single, 18 with double, and 36 with triple vessel disease) were taking beta-adrenergic blocking agents. The mean (SD) maximum heart rate achieved during exercise was 153 (26) beats/min in the group not taking beta blockers and 118 (20) beats $/ \mathrm{min}$ in the group taking beta blockers. False positive results occurred in 14 patients not taking beta blockers and 12 taking them. False negative results occurred in 20 patients not taking beta blockers and in 14 patients taking beta blockers. This difference was not significant $\left(\chi^{2}=1 \cdot 37\right)$.

Electrocardiographic changes in leads A1, B1, C1, and D1 (figure) contributed little to the test as changes in these leads were accompanied by similar changes in other leads in the same territory in all but seven patients; these seven patients had as the only abnormality $Q$ waves in the upper leads. In four of these the $Q$ wave (lead A1) correctly indicated the presence of a right coronary artery lesion. In the three other patients, however, it led to a false diagnosis.
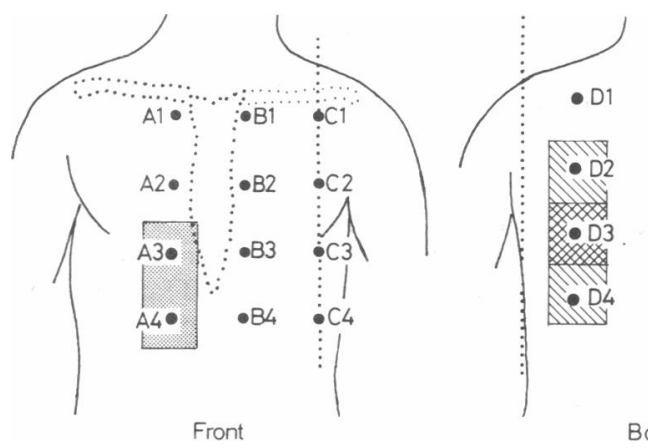

Back

Position of leads on front and back of thorax. In this patient $Q$ waves were present in leads A 3 and A4 at rest (stippled area). During exercise ST segment depression of $3 \mathrm{~mm}$ appeared in lead D3 (cross hatched) and of $2 \mathrm{~mm}$ in leads D2 and D4 (hatched). On angiography the right coronary artery was occluded and the main circumflex $85 \%$ stenosed.

\section{Discussion}

The demand for coronary bypass surgery and the fairly limited resources for coronary angiography mean that greater reliance is placed on non-invasive investigations for screening and follow up of patients. If a screening test is to be incorporated into clinical decision making it should indicate not only the presence or absence of coronary artery disease but also the number of vessels affected. Although the sensitivity $\left(98^{\circ}\right)$ and specificity $\left(88^{\circ}{ }_{0}\right)$ of the test described were not significantly different from those obtained with precordial mapping, ${ }^{14}$ this is the first time that lesions in individual coronary artery territories have been detected with an electrocardiographic exercise test.

Two factors played an important part-namely, the position of the leads on the chest wall and the combination of the three separate electrocardiographic criteria of myocardial disease. The position of the leads was such that they appeared to reflect electrical changes in the three main coronary artery territories, thus providing the spatial information. By using multiple criteria the accuracy was improved. Reliance on ST segment changes alone would have resulted in $20 \%$ of appreciable lesions being missed (table III); reliance on lead C3 (conventional V5) alone would have resulted in $25 \%$ of the lesions in the left anterior descending or diagonal artery being missed.

TABLE III-Incidence of electrocardiographic criteria of ischaemia responsible for diagnosis of disease in each coronary artery

\begin{tabular}{|c|c|c|c|}
\hline $\begin{array}{l}S T \text { segment } \\
\text { changes }\end{array}$ & $\begin{array}{l}\text { Appearance of } \\
\text { inverted } U \text { wave }\end{array}$ & $\begin{array}{c}\text { Presence of } \\
Q \text { wave }\end{array}$ & $\begin{array}{l}\text { No of angiographic } \\
\text { lesions detected } \\
\text { by electrocardio- } \\
\text { graphic exercise test }\end{array}$ \\
\hline \multicolumn{4}{|c|}{ Left anterior descending or diagonal artery, or both $(n=113)$} \\
\hline+ & +0 & + & 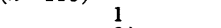 \\
\hline - & + & + & 3* \\
\hline+ & + & - & 4 \\
\hline+ & - & + & 20 \\
\hline+ & - & - & 76 \\
\hline - & + & - & $3^{*}$ \\
\hline- & - & + & $6^{*}$ \\
\hline \multicolumn{4}{|c|}{ Circumflex artery $(n=77)$} \\
\hline+ & - & + & 3 \\
\hline+ & - & - & 65 \\
\hline- & + & - & $1 *$ \\
\hline \multirow{2}{*}{\multicolumn{4}{|c|}{ Right coronary artery $(n=60)$}} \\
\hline & & & \\
\hline+ & - & + & 5 \\
\hline+ & - & - & 27 \\
\hline - & + & - & $1 *$ \\
\hline - & - & + & $27^{*}$ \\
\hline
\end{tabular}

* Detection of disease as result of inverted $U$ wave or $Q$ wave, or both.

Although the criteria used resulted in a high sensitivity, this was not at the expense of any considerable loss in specificity (tables I and II). The patients studied had chest pain suggestive of angina, and there were only 14 women: false positive results are common in women. ${ }^{15}$ The results of this investigation cannot necessarily be extrapolated to other patient populations selected by other criteria. In patients without chest pain the prevalence of the disease will be lower and thus the test would probably have a decreased predictive value. ${ }^{16} 17$

The results suggest that this test may be used in patients who are taking beta blocking agents. This is important since many patients referred for investigation of chest pain are taking these drugs and there is a recognised risk of withdrawing them abruptly. The exact effect of these drugs on the sensitivity and specificity of the test has still to be determined by doing the test in the same patients before and after administration of beta blocking agents.

The high sensitivity and specificity achieved by this technique (table I) in symptomatic patients means that when the result is negative further investigation by angiography is unnecessary. In addition, the ability of this method to determine the presence of single, double, or triple vessel disease non-invasively means that clinical decisions may be made in some patients with angina without resorting to arteriography. For example, a patient with fairly mild angina well controlled by medication would not be considered for coronary angiography if the exercise test showed disease in only one vessel. On the other hand, coronary angiography with a view to surgery should be done if the test indicates either three vessel disease or appreciable lesions in the territories of the left anterior descending or diagonal plus circumflex arteries. This should ensure that all patients with appreciable left main stem lesions will undergo angiography (table II). This is of considerable importance since surgery increases longevity in patients with left main stem or three vessel disease. ${ }^{18}$

The lack of any contribution of the upper leads to the accuracy of the test suggests that they might be omitted. A 12 lead system would be cheaper and easier to handle and could be set up in any hospital equipped with three channel recorders.

The test described in this paper is an objective non-invasive investigation, easy to perform, and repeatable at frequent intervals. It may be used in clinical trials that in the past have used end points such as myocardial infarction or death. In addition, it may provide not only a screening test for the selection of patients for angiography but also a more objective test for 
postoperative follow up and a better understanding of the natural history of ischaemic heart disease.

We thank HEART and the A G Leventis Foundation for financial support.

\section{References}

I Blackburn H. The exercise electrocardiogram in diagnosis. Cardiology 1977;62:190-205.

2 Selwyn AP, Fox K, Eves M, et al. Myocardial ischaemia in patients with frequent angina pectoris. $\mathrm{Br}$ Med F 1978;ii:1594-6.

3 Fox K, Selwyn A, Shillingford J. Praecordial electrocardiographic mapping after exercise in the diagnosis of coronary artery disease. $A m \mathfrak{F}$ Cardiol $1979 ; 43$ :541-6.

4 Fox K, Selwyn A, Oakley D, et al. Relation between the praecordial projection of ST segment changes after exercise and coronary angiographic findings. Am 7 Cardiol $1979 ; 44: 1068-75$.

s Selwyn A, Shillingford JP. Praecordial mapping of $Q$ waves and RS ratio changes in acute myocardial infarction. Cardiovasc Res 1977;11 167-71.

- Fox KM, Selwyn AP, Shillingford JP. Projection of electrocardiographic signs in praecordial maps after exercise in patients with ischaemic heart disease. Br Heart $\mathcal{F} 1979 ; 42: 416-21$.

${ }^{7}$ Elamin MS, Boyle R, Kardash MM, et al. Accurate detection of coronary heart disease by new exercise test. Br Heart $\mathcal{F}$ 1982;48:311-20.
Cooksey SD, Dunn M, Massie E. Clinical vectorcardiography. 2nd ed. Chicago: Year Book Medical Publishers, 1977:94.

${ }^{9}$ Gerson MC, Phillips JF, Morris SN, et al. Exercise induced U-wave inversion as a marker of stenosis of the left anterior descending coronary artery. Circulation 1979;60:1014-20.

${ }^{10}$ Horan LG, Flowers NC, Johnson JC. Significance of the diagnostic Q wave in myocardiac infarction. Circulation $1971 ; 43: 428-36$.

"Scandinavian Committee on ECG classification. The "Minnesota code" for ECG classification. Adaptation to CR leads and modifications of the code for ECGs, recorded during and after exercise. Acta Med Scand [suppl] 1967;481:1-26.

12 Judkins MP. Selective coronary arteriography. A direct percutaneous transfemoral technique. Radiology 1967;89:815-24.

13 Sones FM, Shirey EK. Cine coronary arteriography. Mod Concepts Cardiovasc Dis $1962 ; 31: 735-8$.

14 Fox K, England D, Jonathan A, et al. Praecordial surface mapping of the exercise ECG. Br f Hosp Med 1982;27:291-9.

15 Sketch M, Mohiudahin S, Lynch J. Significant sex differences in the correlation of electrocardiographic exercise testing and coronary angiograms. Am $\mathcal{f}$ Cardiol $1975 ; 36: 169-73$.

16 Jolliffe RW. Quantitative aspects of clinical judgment. Am $\mathcal{Y}$ Med 1973; $55: 431-3$.

17 Diamond GA, Forester JS. Analysis of probability as an aid in the clinical diagnosis of coronary artery disease. $N$ Engl $f$ Med 1979;300: 1350-8.

18 Second Interim Report by the European Coronary Surgery Study Group. Prospective randomised study of coronary artery bypass surgery in stable angina pectoris. Lancet 1980 ;ii:491-5.

무

\title{
Effect of daily oral omeprazole on 24 hour intragastric acidity
}

\author{
R P WALT, M DE F A GOMES, E C WOOD, L H LOGAN, R E POUNDER
}

\begin{abstract}
Twenty four hour intragastric acidity was measured in nine patients with duodenal ulcer before and after one week of treatment with oral omeprazole $30 \mathrm{mg}$ daily, a drug that inhibits gastric secretion by inhibition of parietal cell $\mathrm{H}^{+} \mathrm{K}^{+}$adenosinetriphosphatase (ATPase). Omeprazole virtually eliminated intragastric acidity in all patients: the median 24 hour intragastric $\mathrm{pH}$ rose from 1.4 to 5.3 and the mean hourly hydrogen ion activity fell from 38.50 to $1.95 \mathrm{mmol}(\mathrm{mEq}) / 1 \quad(p<0.001)$. This inhibition of 24 hour intragastric acidity is more profound than that previously reported with either cimetidine $1 \mathrm{~g}$ daily or ranitidine $300 \mathrm{mg}$ daily.
\end{abstract}

\section{Introduction}

Omeprazole is a new substituted benzimidazole (fig 1). Substituted benzimidazoles inhibit the action of the enzyme $\mathrm{H}^{+} \mathrm{K}^{+}$ adenosinetriphosphatase (ATPase), which is postulated to be the proton pump of the parietal cell. ${ }^{1-7}$ Omeprazole inhibits both basal and pentagastrin stimulated acid secretion in normal

Academic Department of Medicine, Royal Free Hospital School of Medicine (University of London), London NW3 2PF

R P WALT, MRCP, medical registrar

$M$ DE F A GOMES, MRCP, research registrar

E C WOOD, PHD, clinical medical student

L H LOGAN, BSC, scientific officer

R E POUNDER, MD, MRCP, senior lecturer in medicine

Correspondence to: Dr R E Pounder. man, ${ }^{8} 9$ and basal secretion in patients with the ZollingerEllison syndrome. ${ }^{10}$ The acid inhibitory effect of omeprazole is non-competitive and of prolonged duration. ${ }^{4}$ The maximal antisecretory effect is observed after several days of treatment. ${ }^{8}$

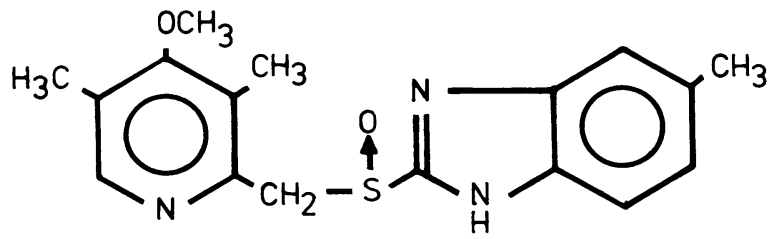

FIG 1-Chemical structure of omeprazole.

In earlier 24 hour studies with cimetidine ${ }^{111^{12}}$ and ranitidine ${ }^{13}$ we defined the effective dose of these antisecretory drugs before the start of clinical trials: both $\mathrm{H}_{2}$ receptor antagonists decrease mean intragastric hydrogen ion activity by approximately two thirds over 24 hours in patients with duodenal ulcer. Omeprazole appears to be a more potent inhibitor of acid secretion than either cimetidine or ranitidine. ${ }^{89}$ In the present study we measured the effect of a daily oral dose of omeprazole $30 \mathrm{mg}$ on 24 hour intragastric acidity.

\section{Patients and methods}

Nine men with endoscopically diagnosed duodenal ulcers in remission were studied. The mean age of the patients was $47 \cdot 4$ (range 22-66) and their mean weight $69 \cdot 2 \mathrm{~kg}$ (range $56 \cdot 8-85.0 \mathrm{~kg}$ ). Five were smokers, who consumed on average 14 cigarettes during each study day. No patient received any antisecretory drugs within 